\title{
AOR
}

Selected Papers of \#AoIR2018:

The $19^{\text {th }}$ Annual Conference of the

Association of Internet Researchers

Montréal, Canada / 10-13 October 2018

\section{THE EFFECTS OF INFORMATION PRODUCTION PROCESS ON EXPERIENCE AND EVALUATION}

\author{
Yonit Rusho \\ University of Haifa, Israel; Shenkar, Israel \\ Daphne R. Raban \\ University of Haifa, Israel
}

\section{Introduction}

Research to date on the value of information has mostly focused on the consumption side of information, namely, that consumers need to experience information in order to evaluate it. When it comes to digital media, users have multiple roles as audiences, consumers and producers. In this context, materiality is applied to assess the role that technological components play in the interaction between user and digital media (Mollen, Saariekoto \& Kleut, 2016). The concurrent consumption and production of information raises questions as to the influence of information production on information value perception. To this end, we conceptualize the information production process. In order to research the influence of information production on value perception, we examine the influence of the conceptual production model on the visible structures that form our informational experience and evaluation.

The fundamental assumption in this research is that value perception may change as a result of engaging in production. This assumption comes from recent research which coined the "Ikea Effect", which showed that value perception increases when people engage in making physical objects (Norton, Mochon \& Ariely, 2012). This study applies the lkea Effect theory from the physical world to the production of digital information goods. We examine the relations between producing, consuming, experiencing and evaluating information. Furthermore, this study examines the boundaries of value perception for producers of information. Boundaries are explored by varying the experience intensity, which is represented by several levels of collaborative production.

\section{Rationale}

ISuggested Citation (APA): Lastname, Firstinitial. (2018, October 10-13). THE EFFECTS OF INFORMATION PRODUCTION PROCESS ON EXPERIENCE AND EVALUATION. Paper presented at AolR 2018: The 19th Annual Conference of the Association of Internet Researchers. Montréal, Canada: AolR. Retrieved from http://spir.aoir.org. 
In order to research the effect of information production and consumption on value perception, information in this research is considered as an economic good, which can be transferred, has some utility (usefulness), is capable of having an economic value attached to it (Bates, 1990) and is an experience good (Van Alstyne, 1999). For example, a book, a song or a software are considered as information goods. Lievrouw (2014) refers to materiality as the usefulness and usability attributes of objects. Raban (2007) emphasizes the subjective nature of value perception by suggesting that the value of information perceived by a user is dynamic.

From an economic aspect, the subjective perception of information causes a gap between the amount consumers are willingness-to-pay (WTP) for a good and the payment sellers are willing to accept (WTA) (Raban \& Rafaeli, 2006). Similarly, we expect the price a consumer agrees to pay for a book will be lower than the price that the author, who is the producer of the book, would be willing to accept in order to sell it. Information production is a value-added process and is defined in this research as a five-stage cycle, earlier suggested by Kotonya and Sommerville's (1998) as a software production conceptual model: (1) specification (2) design (3) implementation (4) validation (5) evolution. Figure 1 presents the model for information production and is the basis for the production activity in the current study.

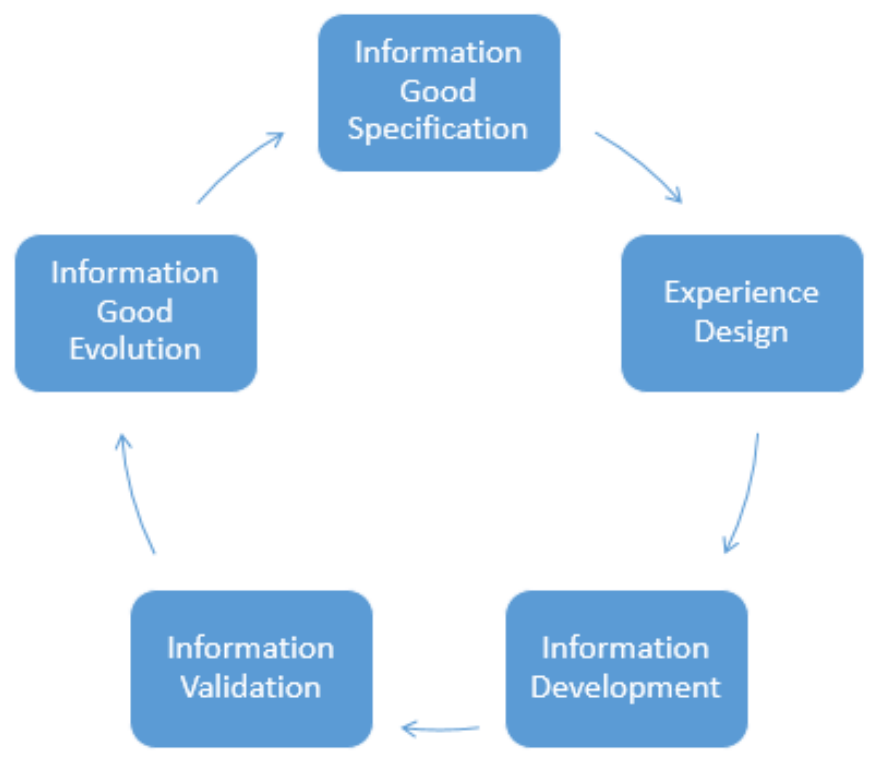

Fig. 1: The process of information good production

In order to research the effect of information production on value perception, following are the research hypotheses:

$\mathrm{H} 1$ : Production experience of information is associated with higher perceived value post experience than consumption experience

$\mathrm{H} 2$ : Value perception post production is higher than before the production

H3: High intensity level of experience causes a negative relationship between value perception and level of experience

\section{Method}

An experiment included a Web-based assignment, where information experience (consumption or production of information) was controlled. 651 participants took part in 
a set of 16 independent experiments. Subjective information value before experience (measured by WTP for consumers and WTA for producers) and perceived information value post experience were measured. The change in value perception was calculated based on the observed variables.

In the assignment participants were asked to display their knowledge regarding Web accessibility regulations and implementation. Participants were randomly assigned to one of the following groups: single consumer/producer, information evaluation before/after experiencing information, peer-producers in various numbers. In the consumption experience group, participants read a brochure with information about Web Accessibility. In the production experience group, participants created the same information described above. In the peer-production group, participants saw a listing of virtual peers and a voting mechanism reflecting group decisions.

WTP and WTA bids were collected based on the incentive-compatible BDM method mechanism (Becker, DeGroot \& Marschak, 1964). BDM enables the extraction of true private values, by informing consumers about the existing of a (random) hidden market price. The assurance of paying or receiving market prices promotes truthful bidding of private subjective values for objects of trade.

\section{Results}

(1) Producers evaluate the information after the experience higher than consumers ( $p=.001$. Consumers: $\mathrm{N}=41$, average value: 299 , std. deviation: 512 . Producers: $\mathrm{N}=48$, average value: 1653 , std. deviation: 2581) (2) A statistically significant effect $p=.000$ was found between subjective value before and after production (before production: $n=52$ average 245; after production: $n=27$ average 1653); (3) Value perception measured before the production by a single producer is lower than value perception by peer-producers ( $p=.001$. Single producer average value: 27.245 . Average value by a producer in a group of 3 peer-producers: $918.57 ; p=.000$. Average value by a producer in a group of 27 peer-producers: $1005.40 ; p=.008$. Average value by a producer in a group of 243 peer-producers: 808.32). H3 was accepted while also revealing a boundary of value perception. Figure 2 displays the relation between number of collaborators on value of information:

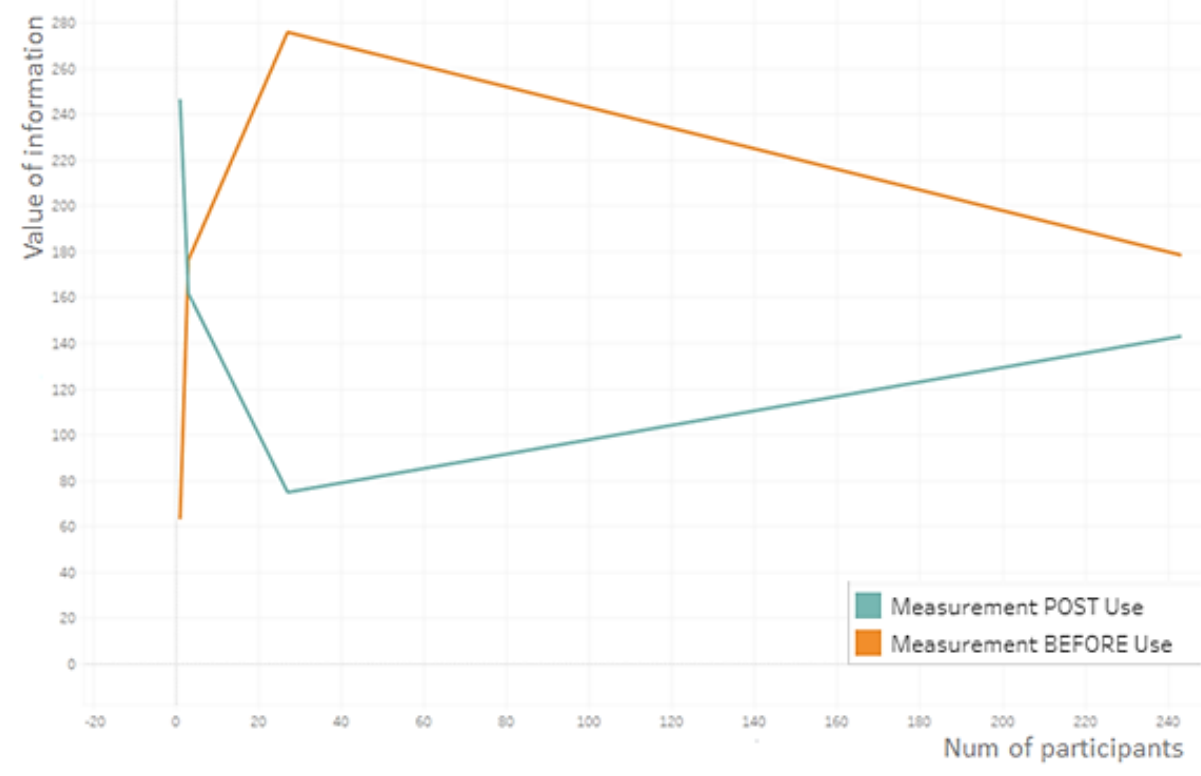

Fig. 2: Perceived values measured in peer-production tasks before and after experience 


\section{Discussion}

The "Ikea Effect" for information goods shows that production affects value perception. Meaning, labor put into production process is translated to perceived value of information. Consequently, information production has a greater impact than merely selling a good that was not self-made and greater value than in purchasing In addition, crowdsourcing is more valued than the labor of individual producers when measured before production. After production, crowdsourcing devalues information.

\section{References}

Bates, B. J. (1990). Information as an economic good: A re-evaluation of theoretical approaches. Mediation, Information, and Communication. Information and Behavior, 3 , 379-394.

Becker, G. M., DeGroot, M. H., \& Marschak, J. (1964). Measuring utility by a singleresponse sequential method. Behavioral Science, 9(3), 226-232.

Dourish, P., \& Mazmanian, M. (2011, June). Media as material: Information representations as material foundations for organizational practice. In Third international symposium on process organization studies (p. 92).

Kotonya, G., \& Sommerville, I. (1998). Requirements engineering: Processes and techniques Wiley Publishing.

Lievrouw, L. A. (2014). Materiality and media in communication and technology studies: An unfinished project. Media technologies: Essays on communication, materiality, and society, 21-51.

Mollen, A., Saariekoto, M., \& Kleut, J. (2016). Intersecting audience activities: An audience studies perspective on the materiality of design, platforms and interfaces. Participations, 13(1), 360-373.

Norton, M. I., Mochon, D., \& Ariely, D. (2012). The IKEA effect: When labor leads to love. Journal of consumer psychology, 22(3), 453-460.

Raban, D. R. and S. Rafaeli (2006). "The effect of source nature and status on the subjective value of information." Journal of the American Society for Information Science and Technology 57(3): 321-329.

Rafaeli, S., \& Raban, D. R. (2003). Experimental investigation of the subjective value of information in trading.

Van Alstyne, M. V. (1999). A proposal for valuing information and instrumental goods. Proceedings of the 20th International Conference on Information Systems, pp. 328-345. 